\title{
Imaging Technology
}

National Cancer Institute

\section{Source}

National Cancer Institute. Imaging Technology. NCI Thesaurus. Code C18843.

Any of a number of technologies that permits the visualization and acquisition of images

into a physical or electronic record. 